\title{
Quenching of Collision between the Solute Molecules in the Nanochannel of MCM-41: A Spin-Probe ESR Study on the Alcoholic Solutions
}

\section{(Supporting Data)}

\author{
Masaharu Okazaki* and Kazumi Toriyama
}

Research Institute of Instrumentation Frontier,

National Institute of Advanced Industrial Science and Technology (AIST), 2266-98, Shimoshidami, Moriyama-ku, Nagoya, 463-8560, Japan.

\section{I): Surface area and the volume and the diameter of nanochannel}

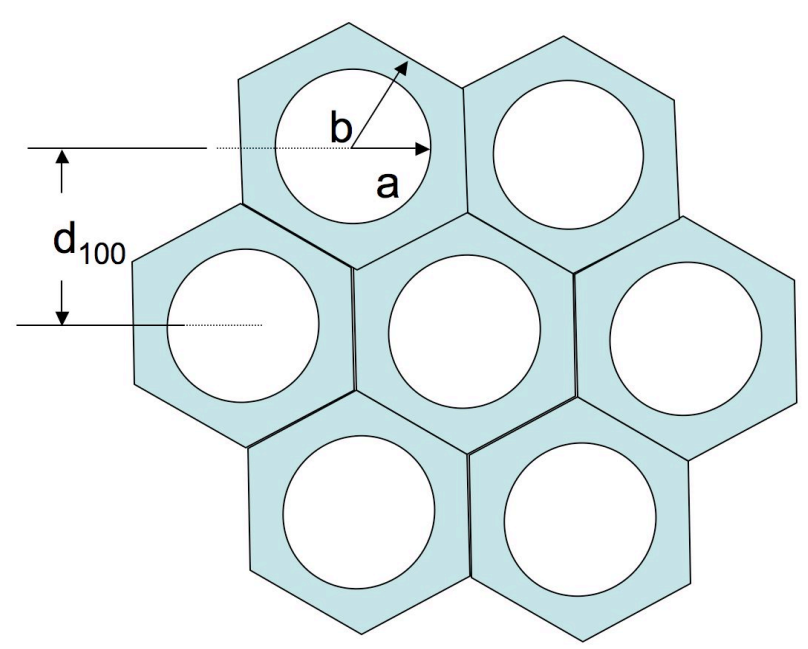

Figure 1s: Model Structure of MCM-41

The volume of the nanochannel of MCM-41(16) and MCM-41(10) can be calculated from: lattice constant d(100) $\left(3.765 \mathrm{~nm}\right.$ and $3.107 \mathrm{~nm}$, respectively ); surface area of $S_{\text {out }} \mathrm{m}^{2} / \mathrm{g}(980 \mathrm{~m} 2 / \mathrm{g}$ and 870 $\mathrm{m} 2 / \mathrm{g}$, respectively); and the silica density of 2.25 .

The figure shows the sectional view of a model particle of MCM-41, which is a bundle of hexagonal pillars with cylindrical hollow (radius $a=\rho b$ ). The number of the pillars $(N)$ is expressed as $N=3 n^{2}+3 n+1$, if the bundle have the hexagonal symmetry. Here $2 n+1$ represents the number of layers. The area of the outer surface and that of the inner holes are: $S_{\text {out }}=6 b(2 n+1) h$ and 
$S_{\text {hole }}=2 \pi \rho b\left(3 n^{2}+3 n+1\right) h$, respectively, where $h$ is the height of the pillar. Thus, the former area can be neglected if $n$ is large enough. For the MCM-41 particle with the diameter of $5 \mu \mathrm{m}, \mathrm{n}$ is larger than 1000 , thus the ratio $S_{O U T} / S_{I N}=2 / \pi \rho n=\sim 0.001$. So, we consider one hexagonal pillar with cylindrical hole without outer surface hereafter. For this model:

$$
V_{\text {hole }}=\pi \rho^{2} b^{2} h \ldots(1) ; S_{\text {hole }}=2 \pi \rho b h \ldots .(2) ; V_{\text {SiO2 }}=\left(2 \sqrt{3}-\pi \rho^{2}\right) b^{2} h
$$

Here, $b=d_{100} / \sqrt{3}, \mathrm{~V}_{\mathrm{SiO} 2}=1.0 / 2.25 * 10^{-6} \mathrm{~m}^{2} / \mathrm{g}$. The calculated volume of the nanochannel is 0.921 $\mathrm{mL} / \mathrm{g}$ at $\rho=0.8624(\mathrm{a}=3.75 \mathrm{~nm})$ for MCM-41(16) and $0.63 \mathrm{~mL} / \mathrm{g}$ at $\rho=0.803(2.88 \mathrm{~nm})$ for MCM-41(10). The amount of solution to fill the nanochannel was a little less than the above calculated value judging from the ESR spectrum. These are $0.9 \mathrm{~mL} / \mathrm{g}$ and $0.5 \mathrm{~mL} / \mathrm{g}$, respectively.

\section{II) Glassware for the sample preparation}

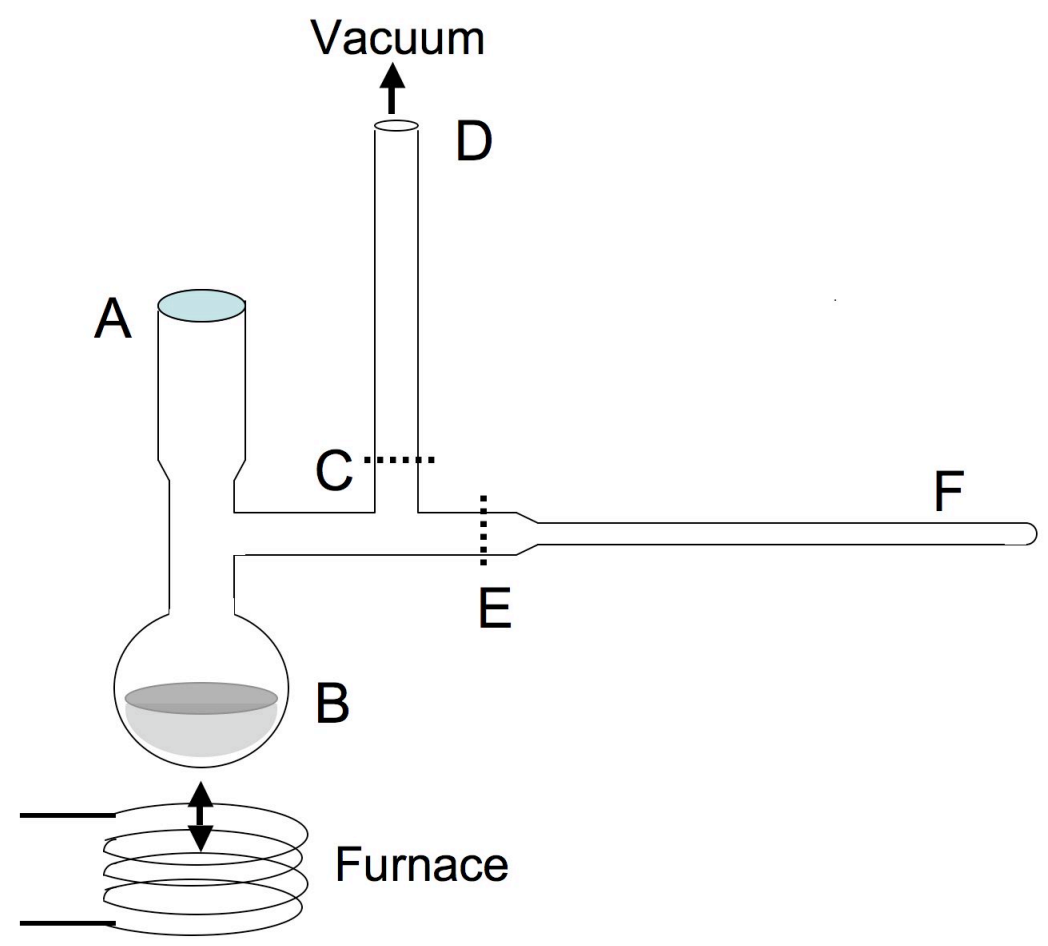

Figure 2S. A glass apparatus for sample preparation and a coil furnace to dehydrate the MCM-41 powder

A screw cap with a septum is equipped at A. The cap is removed when MCM-41 powder is loaded into B. After dehydration of MCM-41 in vacuum, the sample solution was charged from septum A, and degassed. After vigorous shaking for a while the glassware is fused off at C. Argon gas is then injected from septum A by syringe. The sample powder in B is moved to F, and the sample cell is fused off at $\mathrm{E}$.

\section{III) ESR spectrum of DTBN in ethanol}



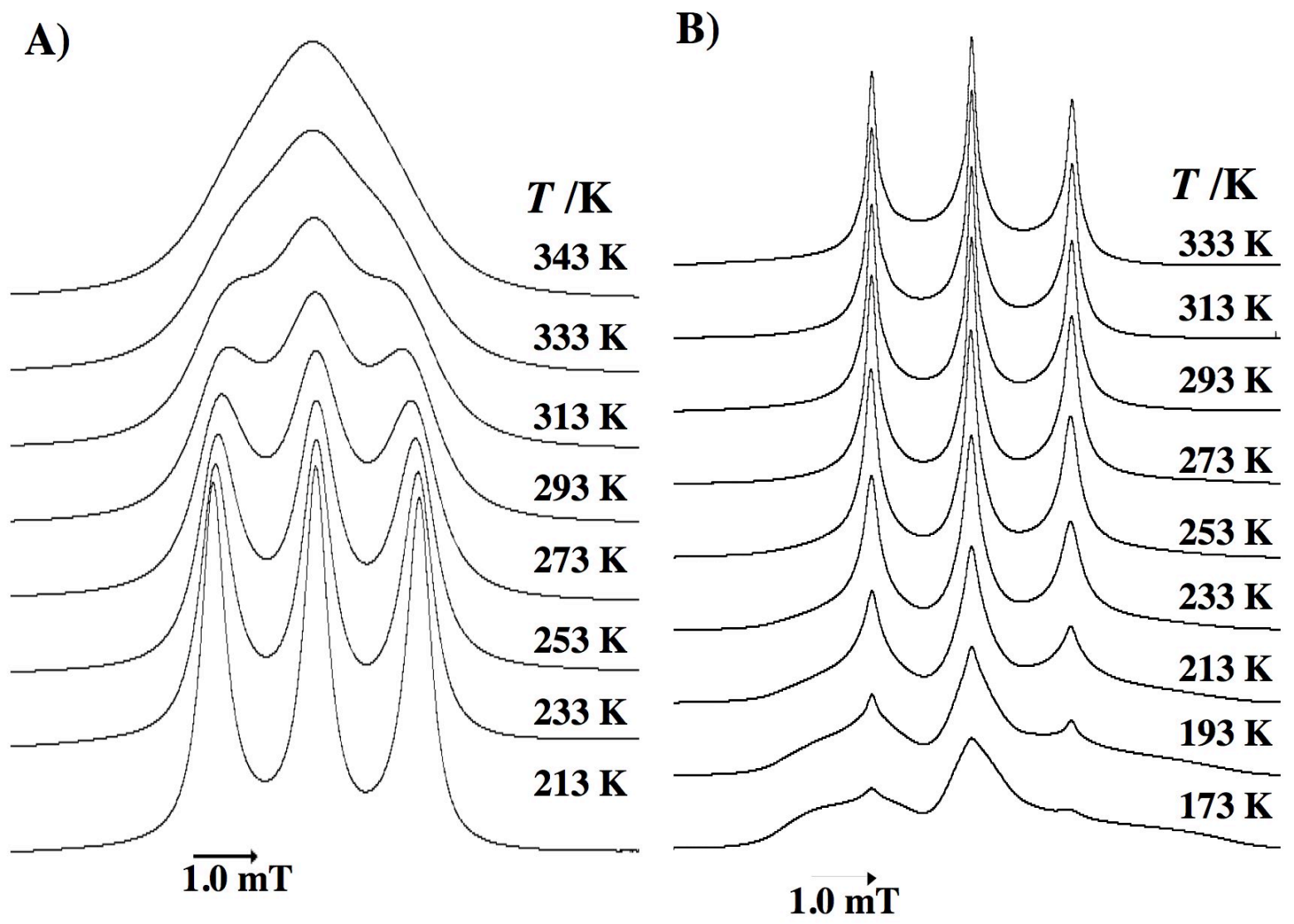

Figure 3s)

ESR spectra of DTBN in ethanol at $30 \mathrm{mM}$ : A) in the bulk solution, B) encapsulated in the nanochannel of MCM-41(10). 


\section{IV): Viscosity of 2-propanol}

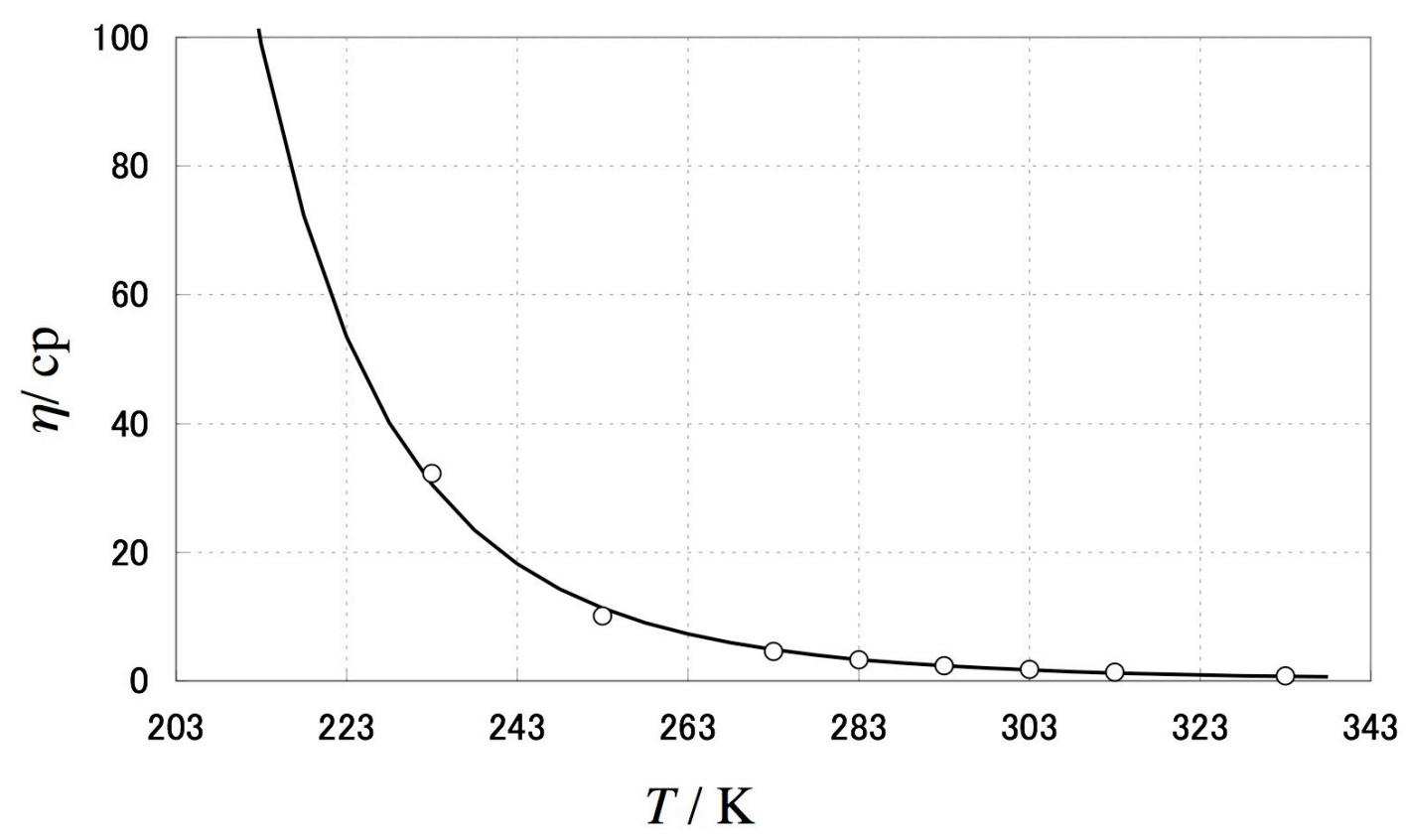

Figure 4s:

Viscosity of 2propanol as the function of temperature. The curve for the estimation of viscosity at temperatures which are not available in the data base has been calculated by the equation $\eta(\mathrm{T})=\mathrm{a} * \exp (\Delta E /$ $\mathrm{RT}$ ) with $\mathrm{a}=0.00011$ and $\Delta \mathrm{E}=2.92 * 10^{3} \mathrm{R}$. Here, the

parameters were obtained in fitting the viscosity data in the curve. Circle: data taken from Handbook of Chemistry, Volume(II) for Basic Chemistry; ed. Chemical Society of Japan: Japan; p 45, Maruzen Publishing, Tokyo, 1984. 